\title{
CONVERSÃO DE DRENAGEM ENTÉRICA PARA VESICAL POR FÍSTULA DUODENAL APÓS TRANSPLANTE DE PÂNCREAS
}

\author{
Enteric to bladder drainage conversion due to duodenal leak following pancreatic transplantation
}

\begin{abstract}
Tércio Genzini', Fábio Crescentini',Huda M Noujaim¹, Matheo Casagrande', Hugo Abensur², Giovanni Scala Marchini,
\end{abstract} Fábio César Miranda Torricelli ${ }^{3}$, Marcelo Perosa de Miranda ${ }^{1}$

\begin{abstract}
RESUMO
Objetivo: 0 transplante de pâncreas constitui o único método capaz de restabelecer por completo o controle glicêmico sem o uso de insul ina exógena. A drenagem exócrina do enxerto pancreático permanece em discussão. 0 objetivo desse relato é expor 0 caso de transplante de pâncreas e rim simultâneo com drenagem entérica submetido à cirurgia de conversão para drenagem vesical, com boa evolução após fístula duodeno-entérica. Método e Critério: Paciente de 36 anos do sexo feminino, portadora de diabetes mellitus tipo I há 23 anos, foi submetida ao transplante de pâncreas e rim simultâneo com drenagem entérica. Houve boa evolução inicial, mas evoluiu com fístula duodenal. Foi submetida a duas intervenções cirúrgicas, sendo que, na segunda, realizou-se conversão para drenagem vesical com sucesso. Discussão e Condusão: A opção cirúrgica de conversão de drenagem entérica para vesical após o transplante de pâncreas é factível em casos nos quais o risco gerado ao paciente seja compensatório. São potencial mente elegíveis para esse procedimento pacientes com fístulas entéricas após transplante duplo com drenagem entérica.
\end{abstract}

Descritores: transplante, pâncreas, conversão vesical, drenagem.

\section{Grau acadêmico:}

1. Cirurgião da HEPATO - Hepatologia, Aparelho Digestivo e Transplantes de Órgãos.

2. Nefrologista.

3. Acadêmico da FMUSP.

Instituição:

HEPATO - Hepatologia, Aparelho Digestivo e Transplantes de Órgãos.

Hospital São Camilo

Correspondência:

Giovanni Scala Marchini - Av. Mandaqui, 63 - Bairro do Limão - São Paulo/SP CEP: 02550-000

Fone: 55113965 6135/Celular: 551181798186

E-mail: giovanni_marchini@yahoo.com.br

Recebido em: 06/09/2005

Aceito em: 30/09/2005

\section{INTRODUÇÃO}

0 transplante de pâncreas (TP) constitui o único método capaz de restabelecer por completo o controle glicêmico sem o uso de insulina exógena, conferindo ao paciente diabético melhor qualidade de vida e estabilização e/ou reversão das complicações secundárias do diabetes mellitus (DM ). Contudo, por características peculiares ao pâncreas e às técnicas cirúrgicas até então utilizadas, o TP é acompanhado de freqüentes complicações cirúrgicas e metabólicas.

A drenagem exócrina do enxerto pancreático permanece em discussão. Pode ser vesical, seguida de menor incidência de complicações técnicas mas com seqüelas metabólicas que exigem conversão entérica de cerca de $20 \%$ dos casos ao longo dos anos, ou entérica, com maior risco de trombose ou sepsis, mas sem a acidose ou complicações urológicas da drenagem vesical. Cabe ao grupo de transplante a escol ha final acerca da técnica, segundo seu aprendizado e segurança, cada uma delas apresentando seus riscos e benefícios. 0 registro internacional de TP (IPTR) mostra tendência crescente à drenagem entérica em todas as modal idades de TP, ${ }^{1}$ sendo raros os rel atos de conversão para drenagem vesical.

0 objetivo deste relato é apresentar um caso de paciente receptor de transplante de pâncreas e rim simultâneos (TPRS) com drenagem entérica, posteriormente submetido à cirurgia de conversão para drenagem vesical com boa evolução após fístula duodeno-entérica. 


\section{RELATO DE CASO}

Paciente de 36 anos do sexo feminino, portadora de diabetes mellitus tipo I (DM) há 23 anos, tendo desenvolvido retinopatia, neuropatia periférica, nefropatia em fase dialítica há quatro anos e fazendo uso de 30 unidades de insulina NPH diariamente. A mesma foi submetida ao TPRS. A imunossupressão consistiu de indução com OKT 3 e manutenção com tacrolimus, M M F e prednisona. A técnica operatória consistiu em incisão única, mediana e transplante de pâncreas órgão total com drenagem exócrina entérica e venosa sistêmica, sendo o pâncreas locado na fossa ilíaca direita do receptor. 0 rim foi implantado na fossa ilíaca esquerda por acesso transperitonial. Um dreno de Jackson Pratt (J P) foi colocado ao longo do pâncreas. As características de paciente e transplante estão expostas na tabela 1.

Tabela 1 - Descrição dos dados logísticos

\begin{tabular}{ll}
\hline DADOS CLÍNICOS DO PACIENTE & \\
\hline Idade & 36 anos \\
Sexo & Feminino \\
Tempo de Diabetes & 23 anos
\end{tabular}

Complicações Secundárias ao DM

Retinopatia
Neuropatia Periférica
Nefropatia dialítica (4 anos)
30 Unidades

Dose diária de Insulina NPH TÉCNICA OPERATÓRIA NO TPRS Pâncreas Transplante de pâncreas de órgão total

Drenagem exócrina

Entérica

Drenagem venosa

Sistêmica

Local

Fossa llíaca Direita

Rim

Local Artéria, Veia, Ureter únicos

IMUNOSSUPRESSÃO

Indução Fossa llíaca Esquerda

Manutenção

OKT3

DM - Diabetes Mellitus; TPRS - transplante de pâncreas e rim simultâneos; MMF - Micofenolato Mofetil.

Houve boa evolução nos primeiros dias de pós-operatório (PO), com níveis de glicemias entre 100 e $150 \mathrm{~g} / \mathrm{dl}$ e diurese moderada (4000ml/24hs). 0 dreno apresentava conteúdo sero-hemático com volume de 450 a $550 \mathrm{ml} / 24 \mathrm{hs}$. A presentou valores normais de glicemia de jejum (74), amilase, lipase e creatinina séricos, sendo a amilase do dreno de JP elevada, em torno de $1780 \mathrm{U} / \mathrm{I}$ com aspecto sero-hemático até $03^{\circ} \mathrm{PO}$. A partir do $6^{\circ} \mathrm{PO}$ teve dor abdominal intensa em cólica e diarréia, evoluindo com distensão abdominal, caracterizando quadro de suboclusão intestinal. R aio-X de abdômen mostrou nível líquido em delgado e ultra-sonogsutura revelou distensão gasosa de alças intestinais, mas ausência de coleções. No $7^{\circ} \mathrm{PO}$ a paciente foi submetida à laparotomia exploradora que evidenciou cerca de $300 \mathrm{ml}$ de líquido entérico na cavidade peritonial e dois pontos de perfuração no duodeno, junto à extremidade grampeada de sua segunda porção, os quais foram suturados. A cavidade foi lavada com ceftriaxona e anfotericina B, sendo real izada drenagem da cavidade peritonial com dreno de $\mathrm{P}$. A tabela 2 resume as intervenções cirúrgicas às quais a paciente foi submetida. A paciente evoluiu estável hemodinamicamente, euglicêmica, afebril e com boa recuperação do quadro abdominal. Novamente no $7^{\circ} \mathrm{PO}$, observou-se novo quadro de distensão abdominal, elevação da creatinina para $2.6 \mathrm{mg} / \mathrm{dl}$, e aumento da drenagem para $370 \mathrm{ml}$, além de dosagem de amilase no líquido do dreno muito elevada (1330 U/L).

A paciente foi submetida à nova intervenção cirúrgica, no $14^{\circ}$ PO do transplante. Nesta ocasião foi desfeita a anastomose duodeno-entérica, realizada nova êntero-enteroanastomose jejuno-jejunal para restabelecimento do trânsito intestinal e convertendo-se a drenagem exócrina do enxerto para anastomose duodeno-vesical, além de biópsias pancreática e renal. A cavidade foi novamente lavada e drenada. A paciente evoluiu estável hemodinamicamente, euglicêmica, porém apresentando distensão abdominal leve, ausência de RHA oligúria $(65 \mathrm{ml})$ e febril $\left(38^{\circ} \mathrm{C}\right)$. Laboratorialmente, apresentou-se anêmica ( $\mathrm{Hb}$ de 7,1$)$, com leucocitose (10000), uréia de 78, e creatinina de 3,4. Passou a realizar hemodiálise e necessitou de transfusão de concentrados de hemácias. As intervenções clínicas estão representadas na tabela 3. Hemocultura isolou Enterococcus eE nterobacter cloacae, recebendo então, seqüencialmente, ciprofloxacina, imipenem, amicacina, ampicilina, e gentamicina. N ova USG revelou apenas pequenas coleções de conteúdo hipoecogênico com debris entre as alças em fossas ilíacas. A paciente mel horou do quadro infeccioso, porém com piora da função renal (uréia de 144, creatinina de 5.2 e diurese de $420 \mathrm{ml}$ ). U réia e creatinina mantiveram-se elevadas e novas sessões de hemodiálise e transfusões de hemácias foram necessárias.

No $18^{\circ} \mathrm{PO}$ a paciente apresentou melhora significante do quadro clínico e teve alta da UTI, mantendo ainda níveis de uréia e creatinina elevados. Evoluiu com piora da função renal e anúria atribuída à necrose tubular aguda, decorrente do quadro infeccioso. Houve então mel hora da leucometria e identificou-se Pseudomonas aeruginosa multi-resistente na urocultura, sendo então iniciado polimixina B em associação à Vancomicina, mantendo-se a imunossupressão com tacrolimus, micofenolato mofetil e prednisona.

A pesar da insuficiência renal, a função pancreática sempre se manteve estável e satisfatória. Entretanto, a secreção exócrina pancreática crescente, verificada pelos níveis crescentes de amilasúria, na presença de anúria renal, levou no $22^{\circ} \mathrm{PO}$ à ocorrência de hematúria vultuosa, seguida de dor abdominal e obstrução vesical por coágulos, sendo necessária cistoscopia com lavagem vesical para remoção dos mesmos. M anteve-se irrigação vesical contínua por $72 \mathrm{hs}$, com resolução da hematúria decorrente de cistite química. A amilasúria estabilizou-se em $1422 \mathrm{U} / \mathrm{h}$.

No $24^{\circ}$ PO repetiu-se biópsia do enxerto renal, cujo resultado foi síndrome hemolítico-urêmica, sendo realizados um pulso de 
Tabela 2 - Intervenções cirúrgicas durante o tempo de internação

\begin{tabular}{|c|c|c|c|}
\hline PO & INDICAÇÃOO & ACHADO & CONDUTA \\
\hline \multirow[t]{5}{*}{7} & Suboclusão intestinal & Líquido entérico na cavidade (300ml) & Lavagem da cavidade \\
\hline & Amilase elevada no dreno (1780 U/L) & Dois pontos de perfuração na segunda porção duodenal & (Anfotericina B e Ceftriaxone) \\
\hline & & & Drenagem com dreno de JP \\
\hline & & & Sutura junto à extremidade \\
\hline & & & grampeada na $2^{\text {a }}$ porção duodenal \\
\hline \multirow[t]{5}{*}{14} & Suboclusão intestinal & Fístula duodenal & Desfeita anastomose duodeno-entérica \\
\hline & Amilase elevada no dreno (1330 U/L) & & Realizada anastomose jejuno-jejunal \\
\hline & Elevação da creatinina $(2.6$ mg/dl) & & Conversão p/ drenagem exócrina vesical \\
\hline & & & Biópsias pancreática e renal \\
\hline & & & Novo dreno de JP \\
\hline \multirow[t]{2}{*}{22} & Amilasúria elevada & Coágulos vesicais & Cistoscopia com lavagem vesical \\
\hline & Cistite/Hematúria & & Irrigação contínua por 72 horas \\
\hline
\end{tabular}

\section{PO - Pós-operatório}

Tabela 3 - Intervenções clínicas durante o tempo de internação.

\section{PO INDICAÇÃO}

15 Oligúria $(65 \mathrm{ml} / 24 \mathrm{hs})$

Elevação da creatinina $(3.4 \mathrm{mg} / \mathrm{dl})$

Anemia ( $\mathrm{Hb} 7,1)$

Hemocultura:

- Enterococcus

- Enterobacter

Leucocitose (10000)

16 Oligúria $(420 \mathrm{ml})$

Elevação da creatinina $(5.2 \mathrm{mg} / \mathrm{dl})$

Anemia persistente

20 Urocultura:

- Pseudomonas aeruginosa

24 Síndrome hemolítico-urêmica

\section{CONDUTA}

Hemodiálise

Transfusão de concentrado de hemácias

Antibioticoterapia sequencial

(Ciprofloxacina, Imipenem, Amicacina, Ampicilina, Gentamicina)

Hemodiálise

Transfusão de concentrado de hemácias

Antibioticoterapia

(Polimixina B, Vancomicina)

Pulso de Solumedrol

\section{PO - pós-operatório}

solumedrol de $500 \mathrm{mg}$ e substituição do tacrol imo por ciclosporina. H ouve mel hora da diurese e resolução do quadro infeccioso após 14 dias de pol imixina B. A paciente obteve mel hora do quadro clínico, recebendo alta no $37^{\circ} \mathrm{PO}$ da $2^{\mathrm{a}}$ reoperação, quando completava 51 dias de transplante.

No seguimento ambulatorial houve melhora progressiva da diurese e redução gradual da necessidade de hemodiálise, que deixou de ser necessária após cinco meses de transplante. A tual mente, a paciente encontra-se insul ino-independente, livre de diálise, com creati nina de $2.3 \mathrm{mg} / \mathrm{dl}$, em uso de ciclosporina, micofenolato e prednisona.

\section{DISCUSSÃO}

0 transplante de pâncreas consiste no tratamento mais eficaz para restauração da normoglicemia e normalização da hemoglobina glicosilada sem a necessidade de insulina exógena. $\mathrm{Na}$ última década, ganhou muita popularidade, mas ainda é seguido de morbidade significante, uma vez que as taxas de complicação ci rúrgica permanecem elevadas, levando 10 a $15 \%$ dos casos à perda do enxerto por causas técnicas. ${ }^{2,3,4}$ Diversos fatores contribuem para esse fato, como a própria morbidade característica da doença em si e o amplo espectro de potenciais complicações envolvendo 0 enxerto pancreático e a imunossupressão que acompanha 0 
transplante. Os índices de complicações podem chegar a 30\% e muitas vezes necessitam de reoperações para o seu tratamento. ${ }^{2,4}$ A s causas mais comuns de relaparotomia são: infecção, trombose, fístula, sangramento e pancreatite. .,6,7,8 $^{-1}$

Recentemente, o aprimoramento nos protocolos deimunossupressão, melhor seleção dos doadores, refinamento do ato cirúrgico e dos cuidados peri-operatórios dos pacientes, além da utilização de melhores drogas no tratamento de infecções e rejeições, têm contribuído para a redução dessas taxas, resultando em melhores sobrevidas, tanto do enxerto pancreático como do paciente transplantado. A pesar dessa mel hora, nota-se diferença nos dados do IPTR quando se compara os TP com drenagem entérica e com drenagem vesical, com vantagens para este segundo grupo, mesmo considerando-se a necessidade de conversão entérica em torno de 20\%, cinco anos após o transplante.

A despeito de seu imenso avanço, alguns aspectos técnicos do transplante de pâncreas permanecem sem consenso totalmente definido, entre eles a drenagem exócrina pancreática. A s vantagens e desvantagens de cada tipo de drenagem já são bem conhecidas. A o se optar pela drenagem exócrina vesical através da anastomose duodeno-vesical, procura-se prevenir a ocorrência de complicações metabólicas, como acidose e necessidade de reposição constante de bicarbonato, e gênito-urinárias, como ITU, uretrites, estenose de uretra e outros, que são freqüentes para parcela considerável dos pacientes. Estima-se que, após cinco anos de transplante, um quarto desses pacientes necessite de cirurgia de conversão para drenagem entérica. Alguns estudos ainda propõem discreta melhora da sobrevida dos enxertos pela monitorização da amilasúria. Q uanto à drenagem entérica, verifica-se maior mortalidade e perda do enxerto em relação à drenagem vesical, apesar de oferecer melhor qualidade de vida pela eliminação das complicações urológicas e metabólicas já descritas.

0 uso da drenagem exócrina entérica é crescente no transplante de pâncreas que acompanha o renal, já que nesses casos o rim serve como marcador de rejeição, mesmo que associado ao maior índice de perda do enxerto pancreático por causa técnica. ${ }^{1} \mathrm{Q}$ uando bem sucedida, a DE demonstra-se mais fisiológica e casos de conversão para drenagem vesical são infreqüentes. Cabe, então, ao cirurgião optar por aquela com a qual tem maior afinidade técnica, segurança e confiança.

De maneira geral, nunca se deve sacrificar o paciente em prol do enxerto pancreático, tendo em vista o fato de não ser essencial à vida e que o retransplante pode ser uma opção com bons resultados aos pacientes que perdem os enxertos. A ssim, frente a uma complicação, as atitudes tomadas em prol do enxerto devem sempre estar amparadas em critérios clínicos, atitudes preventivas e seguras, evitando-se procedimentos que mantenham o paciente em risco. A transplantectomia pode ser uma eficiente alternativa em casos de trombose ou pancreatite, nos quais o enxerto torna-se um fator desencadeante de processos inflamatórios ou infecciosos sistêmicos ou quando possibilita a el iminação da imunossupressão, em situações de sepsi s com risco de vida iminente, situação na qual o enxerto é removido, mesmo que funcionante.

No caso de fístula entérica, como descrito, na ausência de outros fatores de risco, pode-se optar apenas por correção cirúrgica se as condições locais forem favoráveis e permitirem sua reparação. Entretanto, esta atitude mantém o paciente sob o risco de novo quadro semelhante, principalmente quando o problema situa-se no duodeno do enxerto. Nosso paciente apresentava inicialmente boa evolução e optamos pelo procedimento aparentemente mais simples que foi a sutura do duodeno fistulizado junto às linhas de grampeamento. Tal estratégia não foi bem sucedida, uma vez que a área da sutura, provavelmente isquêmica, apesar de seu aspecto intra-operatório parecer bom, voltou a fistulizar, fato que aumentou o risco de mortalidade por sepsis desta paciente. Neste momento, não hesitamos em realizar a conversão da anastomose duodenoentérica para duodeno vesical, mais segura e que permitiria melhor monitorização do enxerto frente a um rim em necrose tubular aguda. 0 preço pago quando da ocorrência de hematúria foi compensado pela recuperação da paciente. A inda discutimos a possibilidade de realizar esta operação como primeira opção no tratamento de caso semel hante de fístula entérica após TP que venha ocorrer um dia.

$\mathrm{N}$ ão existem relatos na literatura a respeito de conversão da drenagem entérica para vesical, demonstrando a raridade de situações em que essa alternativa pode ser empregada. Em estudos prévios, o índice de relaparotomias chega a 32\%, sendo maior no TPRS e variando de 20 a $36 \%$ no transplante com DV e em torno de $65 \%$ na DE ${ }^{5,6,7,9,10}$ Os resultados da DV são melhores que os da DE, mas certamente ainda existe espaço para aperfeiçoamento.

\section{CONCLUSÃO}

A opção cirúrgica de conversão de drenagem exócrina entérica para vesical, após o transplante de pâncreas, éfactível em casos nos quais o risco gerado ao paciente seja compensatório. São potencialmente elegíveis para esse procedimento, pacientes com fístulas entéricas após transplante duplo de pâncreas-rim com drenagem entérica.

\footnotetext{
ABSTRACT

Purpose: Pancreas transplantation remains the only method able to completely reestablish the euglicemic control without using exogen insulin. The pancreatic exocrine drainage is still being discussed. The purpose of this paper is to present a case-report of a patient who underwent a simultaneous pancreas-kidney transplant with enteric drainage, successfully submitted to conversion surgery for bladder drainage due to duodenal leak. Method and Criteria: A 36 years old female patient with diabetes mellitus ty pe 1 for 23 years was submitted to simultaneous pancreas-kidney transplant with enteric drainage. There was a good initial evolution, but the patient presented duodenal leak, being submitted to two surgical interventions. In the second one, the conversion from enteric to bladder drainage was successfully
} 
performed. Disaussion and Condusion: The surgical conversion option from enteric to bladder drainage after pancreas transplant is attractive when the risks offered to the patient are compensatory. Patients under potential situations for this procedure are those presenting duodenal leaking after simultaneous pancreas-kidney transplant with enteric drainage.

Keywords: transplantation, pancreas, bladder conversion, drainage.

\section{REFERÊNCIAS}

1. IPTR 2003 Year Update (http://www.iptr.umn.edu/)

2. Douzdjian V, Abecassi MM, Cooper JL, et al. Incidence, management and significance of surgical complications after pancreatic transplantation. Surg Gynecol Obstet 1993; $177: 451-456$.

3. Eckhoff DE, Sollinger HW. Surgical complications after simultaneous pancreaskidney transplant with bladder drainage. In: Terasaki PI, Cecka JM, eds. Clinical Transplants 1993. Los Angeles: UCLA Tissue Typing Laboratory; 1993:185-191.

4. Ozaki CF, Stratta RJ, Taylor RJ, et al. Surgical complications in solitary pancreas and combined pancreas-kidney transplantation. Am J Surg 1992; 164:546 -551.

5. Bynon JS, Stratta RJ, Taylor RJ, et al. Vascular reconstruction in 105 consecutive pancreas transplants. Transplant Proc 1993; 25:3288-3289.
6. Humar A, Kandaswamy R, Granger D, Gruessner RW, Gruessner AC, Sutherland DER. Decreased Surgical Risks of Pancreas Transplantation in the Modern Era; Ann Surg, 231 (2), 269-275.

7. Modlin CS, Flechner SM, Goormastic M, et al. Should obese patients lose weight before receiving a kidney transplant? Transplantation 1997; 64:599-604.

8. Wright FH, Smith JL, Corry RJ. Postoperative complications of pancreas transplantation. Diabetes 1989; 39:236 -237.

9. Martin X, Lefrancois N, Marechal JM, et al. Pancreas transplantation in Lyon: overall results. Diabetologia 1991; 34:S8-S10.

10. Gruessner AC, Sutherland DER. Pancreas transplant results in the United Network for Organ Sharing (UNOS) United States of America (USA) registry compared with non-USA data in the International Registry. In: Terasaki PI, Cecka JM, eds. Clinical Transplants 1994. Los Angeles: UCLA Tissue Typing Laboratory; 1994:47-68. 